\title{
THE USE OF NUMERICAL MODELLING TO DETERMINE THE CONDITIONS OF REGENERATION OF MEDIUM CARBON STEEL
}

\begin{abstract}
In the paper, the regeneration process of the material in grade C45 using the MAG welding was analysed. The effect of preheating on the properties of the regenerated layers was determined. Preheating technology was used to facilitate the process of regeneration and minimize the risk of imperfections. The use of numerical methods allows one to observe the direction of changes in the properties, structures and emerging stresses and accompanying strains of the elements depending on the temperature applied for preheating.Modeling of the stress state in the element made of medium carbon steel during the regeneration process was performed on original software based on the finite element method. The implemented numerical model consists of three basic elements - thermal phenomena, mechanical phenomena and phase transformations in the solid state. The performed numerical analysis made determining the optimum heating conditions possible, so that the material in the area of joint didn't show tendency to create structural notches associated with the stress state.

Keywords: regeneration process, preheating, numerical modeling, mechanical phenomena, phase transformations
\end{abstract}

\section{Introduction}

Due to the high level of carbon content in the C45 steel, the regeneration of the steel elements requires using the preheating of elements before the repair, it is necessary to obtain the preferred structures of the material and reduce the possibility of cracking within the regenerated layers. The cracks that can occur in the regeneration process are unacceptable by quality standards. The causes of cracks can be: brittle microstructure in the HAZ or weld / padding weld, hydrogen diffuses, high level of tensile stresses $[2,3,5,8,12]$.

The use of computer modelling to perform the qualification process of welding according to the requirements of the norm allows for a reduction in the cost of such tests. The verification of the computer model allows one to select the appropriate conditions of the regeneration of elements used to molds and tools made of steel C45. Application of the assumed conduct provides the possibility of determining the strain, stress state and the fraction of the metallographic structures which are the results of the qualification tests of welding technologies to rebuild the geometrical parameters of elements. The mathematical modelling is justified due to the cost effectiveness of experimental research. Currently, the works in the field of analytical modelling as well as numerical modelling during the welding are conducted to determine formed phases. Analytical models are used to determine the dependence in the model for geometrically simple cases. To analyze the complex shapes and to include a greater number of coupling between the phenomena of the process the numerical models are used [23,24].

In the analysis of the selection of the additional material, the following factors should be taken into account: the required exploitation properties of the layer, hardness, resistance to abrasion, corrosion, impact strength, heat resistance, the available form and welding properties and the cost of additional material. The choice of the proper regeneration method from the available technologies depends on the parameters of the regenerated layer. The main parameter is the size of the defect. In the case of small defects or to protect the element by a thin layer, the spraying technologies can be used. For larger defects or for the thicker layer, the use of the efficient method with the solid or cored wires will be more effective. Regeneration has to recreate the features of the used element, and it should occur in a commercially reasonable manner $[2-5,10,16,18,20$, $21,28]$.

In the case of regeneration on the basis of welding methods, it is necessary to qualify welding technologies according to PN EN 15614-7. The appropriate choice of the technological parameters allows one to obtain the expected effect of regeneration. One of the technological criteria, which should be analyzed, is the type of regenerated material. Steel grade C45 is a material considered as poorly weld able, because it is easily hardened in the HAZ. For these reasons, properly established treatment of preheating should be used. The problem during the qualification is the choice of the proper range of preheating temperature which

\footnotetext{
CZESTOCHOWA UNIVERSITY OF TECHNOLOGY, FACULTY OF MECHANICAL ENGINEERING AND COMPUTER SCIENCE, 21 ARMII KRAJOWEJ AV., 42-201 CZESTOCHOWA, POLAND Corresponding author: rbeczkowski@spaw.pcz.pl
} 
is associated with the cost and time of forming a regenerated surface without the imperfection $[12,13]$.

To perform a full qualification of a semiautomatic welding process in accordance with the requirements of PN EN ISO 15614-7, a few tests can be carried out. The specimen by the non-destructive and destructive testing can be checked. For non-destructive testing, visual and liquid penetrant or magnetic testing can be used. This kind of test is relatively cheap. For destructive testing such as macroscopic and microscopic metallography, a hardness test can also be performed, but this kind of test is expensive. Each of these tests generate some costs of preparing the qualification. Every mistake in qualification causes new costs $[3,5,12,13]$.

\section{Numerical model of regeneration process}

In the paper, the mathematical and numerical model of phenomena occurring during the regeneration process using welding were applied. This model consists of the part responsible for the calculations of the phase transformations in the solid state, the thermal and mechanical phenomena. The elements of the model are related to the appropriate couplings (Fig. 1).

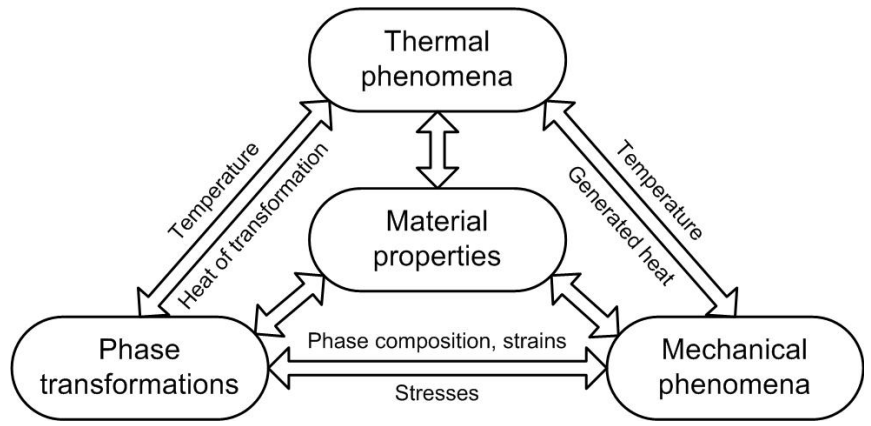

Fig. 1. The diagram of the numerical model of phenomena of regeneration process

The basic element of the regeneration process that decides about the accuracy of the next stage of calculations is the thermal phenomena model. In the paper, the heat transfer equation in the following form was used to determine the field of temperature

$$
\nabla \cdot(\lambda \nabla T)-\rho C \frac{\partial T}{\partial t}=0
$$

where: $T$ is temperature $[\mathrm{K}], t$ is time $[\mathrm{s}], \lambda=\lambda(T)$ is the thermal conductivity $[\mathrm{W} /(\mathrm{mK})], \rho$ is the density $\left[\mathrm{kg} / \mathrm{m}^{3}\right], C$ is the effective thermal capacity $[\mathrm{J} /(\mathrm{kgK})]$.

During the solidification process, the heat of transformation is produced. This heat is included in the model by the modification of the effective heat capacity of the material [7]

$$
C_{e f}=\rho(T) c(T)-\left.\rho_{S} L \frac{\partial f_{S}(T)}{\partial T}\right|_{T_{S}} ^{T_{L}}
$$

where: $L[\mathrm{~J} /(\mathrm{kgK})]$ is latent heat of transformation of the liquid phase-solid phase.
The share of the solid phase is determined by the lever rule

$$
f_{S}=f_{S}(T)=\frac{T_{L}-T}{T_{L}-T_{S}}, T \in\left[T_{L}, T_{S}\right]
$$

where: $T_{L}$ is the temperature of the liquidus line, $T_{S}$-temperature of the solidus line.

To calculate the kinetic of phase transformations in the solid state during the heating and cooling processes, the macroscopic model based on the analysis of CTT diagrams is used $[19,26]$. In this model, to determine the increase of the austenite phase during the heating process, the modified Koistinen-Marburger equation was used $[6,14]$

$$
\tilde{\eta}_{\gamma}(T, t)=1-\exp \left(-\frac{4.60517}{T_{s \gamma}-T_{f \gamma}}\left(T_{s \gamma}-T\right)\right)
$$

where: $T_{s \gamma}$ and $T_{f \gamma}$ are the temperature of the start and finish of austenite transformation.

Wherein the austenite transformation occurs only in the area of heat affected from the weld, it is assumed that the weld, below the solidification temperature, has the austenitic structure.

To calculate the kinetic of austenite $\rightarrow$ ferrite, austenite $\rightarrow$ pearlite, austenite $\rightarrow$ bainite phases the Johnson-Mehl-AvramiKolmogorov equation was used in the form[1]

$$
\begin{aligned}
\eta_{(i)}(T, t)= & \min \left\{\eta_{(i \%)}, \tilde{\eta}_{\gamma}-\sum_{j \neq i} \eta_{j}\right\} . \\
& \left(1-\exp \left(-\frac{0.01005}{t_{s}^{n(T)}} t^{n(T)}\right)\right)
\end{aligned}
$$

where: $\eta_{(i \%)}$ is the final fraction of " $i$ " phase estimation on the basis of CCT diagrams for considered steel, $\tilde{\eta}_{\gamma}$ is a volume fraction of forming austeite, $\eta_{j}$ is the volume fraction of phase formed during the cooling process, $n(T)$ the functions depending on the start and finish times of transformation $\left(t_{s}\right.$ and $\left.t_{f}\right)$.

The increment of the martensite phase is described by the Koistinen-Marburger equation [6,14]

$$
\eta_{M}(T, t)=\left(\tilde{\eta}_{\gamma}-\sum_{i \neq M} \eta_{i}\right)\left(1-\exp \left(-0.0153\left(M_{S}-T\right)\right)\right)
$$

where: $M_{S}$ is the start temperature of martensite transformation.

The martensite tempered fraction resulting from tempering is described by formula

$$
\eta_{(i)}(T, t)=\eta_{M}\left(1-\exp \left(-\frac{0.01005}{t_{s}^{n(T)}} t^{n(T)}\right)\right)
$$

During the welding process, the tempering phenomena has also occurred. In the presented model, the transformation of martensite to tempered martensite is calculated by the modified Avrami equation. The start and finish curves of the tempering transformation are determined by the equation depending on the heating rate [25] 


$$
\begin{aligned}
& T_{S}\left(V_{H}\right)=306.1645 \cdot 1.0007^{V_{H}}\left(V_{H}\right) 0.02514 \\
& T_{F}\left(V_{H}\right)=\frac{1}{0.002588-0.0002854 V_{H}^{0.1568}}
\end{aligned}
$$

where: $V_{H}\left[{ }^{\circ} \mathrm{C} / \mathrm{s}\right]$ - the heating rate.

During the phase transformation, the changes of volume occur. These changes are the results of thermal and structural strains. These strains are calculated by the following equation

$$
\begin{aligned}
\Delta \varepsilon^{T P h} & =\Delta \varepsilon^{T}+\Delta \varepsilon^{P h}, \Delta \varepsilon^{T}=\sum_{i} \alpha_{i}(T) \eta_{i} \Delta T, \\
\Delta \varepsilon^{P h} & =\operatorname{sign}(-\Delta T) \sum_{i} \varepsilon_{i}^{P h}(T) \Delta \eta_{i}
\end{aligned}
$$

where: $\alpha_{i}(T)$ is thermal expansion coefficient for " $i$ " phase, $\varepsilon_{i}^{P h}(T)$ is a strain expansion coefficient for " $i$ " transformation. These values were calculated for the $\mathrm{C} 45$ steel on the basis of experimental research using a dilatometer [6].

In the model of mechanical phenomena, the equilibrium equation was used without mass forces. The equilibrium equations are supplemented by the constitutive relations in the form $[6,7,15]$

$$
\begin{aligned}
& \Delta \boldsymbol{\sigma}=\mathbf{D} \circ \Delta \boldsymbol{\varepsilon}^{\mathbf{e}}+\Delta \mathbf{D} \circ \boldsymbol{\varepsilon}^{\mathbf{e}}, \\
& \Delta \boldsymbol{\varepsilon}^{\mathbf{e}}=\Delta \boldsymbol{\varepsilon}-\Delta \boldsymbol{\varepsilon}^{T}-\Delta \boldsymbol{\varepsilon}^{p h}-\Delta \boldsymbol{\varepsilon}^{p l}-\Delta \boldsymbol{\varepsilon}^{t p}
\end{aligned}
$$

where: $\varepsilon^{e}, \varepsilon, \varepsilon^{T}, \varepsilon^{p h}, \varepsilon^{p l}, \varepsilon^{t p}$ are respectively the elastic, total, thermal, structural, plastic and transformation strain tensors, D is a tensor of material constants.

The plastic strains $\left(\varepsilon^{p l}\right)$ are determined by using the associated plastic flow law with isotropic hardening [15]. To calculate plasticity transformations $\left(\varepsilon^{t p}\right)$ the model based on the Greenwood-Johnson mechanism is used $[11,22]$. The temporary yield point is dependent on the temperature and the phase composition [9].

\section{Examples of calculation}

The numerical simulations of the regeneration process were performed for the plate made of $\mathrm{C} 45$ steel.The computations were performed for the cross-section direction of the forming weld. The depth of the plate is equal $0.01 \mathrm{~m}$, width $0.15 \mathrm{~m}$, whereas the height of padding weld $0.005 \mathrm{~m}$ (Fig. 2). It was assumed that the padding weld was formed in the 8 bead and each has a width that equals $0.01 \mathrm{~m}$. The first weld is located $0.05 \mathrm{~m}$ from the boundary. The shape of the padding weld was approximated to the rectangular element, therefore the angle $90^{\circ}$ is a limit according to the norm ISO 5817 for the level of quality D [12]. The four cases of preheating $T_{0}=20,100,200$, $300^{\circ} \mathrm{C}$ were considered.

The cooling on the boundaries was modeled by the Newton condition. The heat transfer coefficient was adopted for air according to the equation (11), the air temperature was equal $T_{\text {air }}=20^{\circ} \mathrm{C}[17]$

$$
\alpha_{\text {air }}=\left\{\begin{array}{cc}
0.0668 \times T & T_{0}<T<500^{\circ} \mathrm{C} \\
0.231 \times T-82.1 & T \geq 500^{\circ} \mathrm{C}
\end{array}\right.
$$

It was assumed that the nest padding weld is represented by adding the appropriate area in the finite elements mesh. This required performing a simulation for eight different geometries. The dimension of each finite element was equal $\Delta x=0.000625 \mathrm{~m}$, $\Delta y=0.0005 \mathrm{~m}$. It allows one to observe changes in the mechanical phenomena as well as phase transformations in the solid state. The initial temperature of the padding weld was $3000 \mathrm{~K}$. The appearance of the next padding weld was dependent on the value of temperature. For the first case, (the initial temperature of steel plate was equal to the air temperature) the next bead was formed after the full cooling of the steel element. In other cases the next padding weld occurred after reaching the previous padding weld of preheating temperature. The adopted cooling conditions allow for the total disintegration of austenite. In the model of mechanical phenomena, the appropriate boundary conditions were adopted (statically determinate). The thermophysical properties such as: heat transfer coefficient, thermal capacity, density, Young's modulus were defined as a function of temperature, whereas yield point - as a function of temperature and phase composition [9].

Each test consists of 8 cases of simulation following one another. The input data of the following simulation (temperature, phase content, displacement, strains, stresses) are the results of computation for the previous geometry

On the basis of ferrite and pearlite fractions, it can be observed that the first two padding welds are significantly different from the others. For the third and next - the cooling and heating conditions stabilize and the repeatability of the process is better. The most varied results occurred for the first padding weld. This is related to the fact that heat transfer to the regenerated part is carried out by one surface, whereas by the upper, the right and the left surface of the bead is cooled by the air. The choice of the thermal condition of the weld bead, despite large simplification, seems to be correct. The depth of penetration obtained in the simulation (see Fig. 4a) is comparable with the experiment (Fig. 5). As expected, the increase of the initial temperature of the surfacing material, keeping the initial temperature of the padding weld,

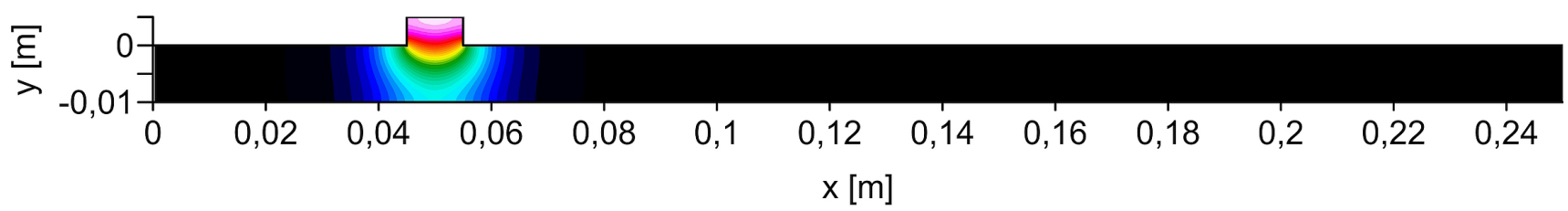

Fig. 2. The temperature field for the first preheating $\left(T_{0}=20^{\circ} \mathrm{C}\right)$ after the time $t=4 \mathrm{~s}$ 
a)

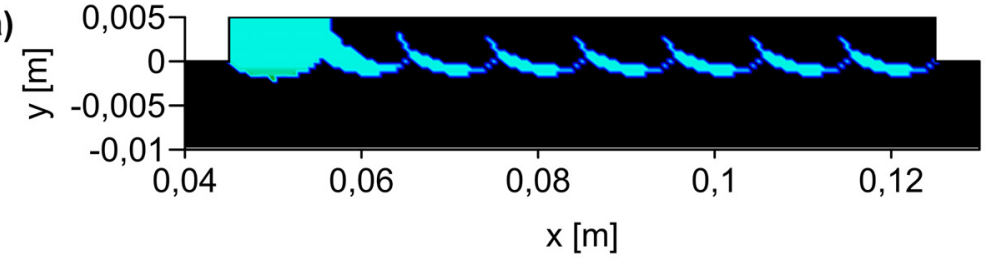

b)

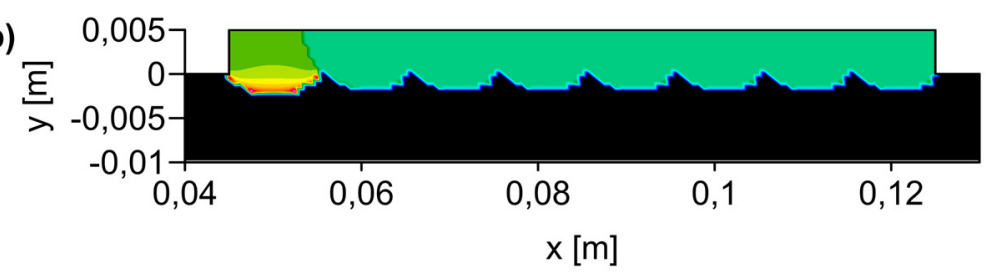

c)

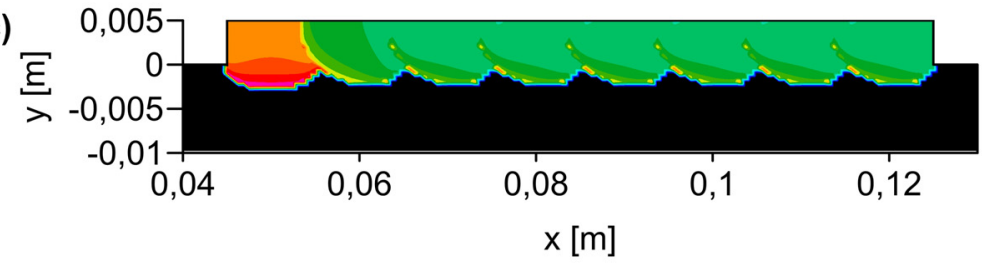

d)

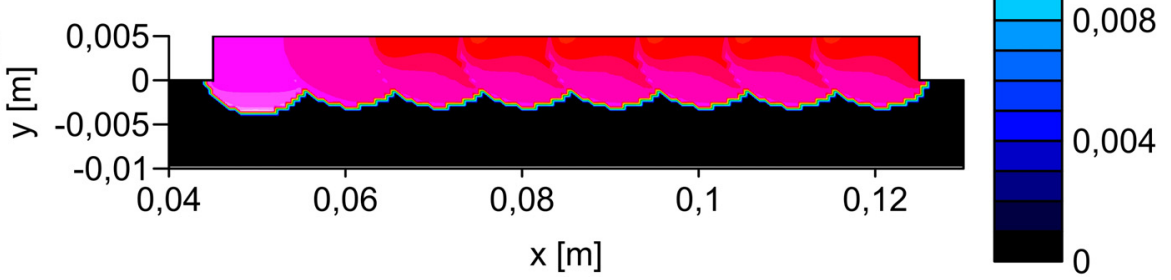

Fig. 3. Ferrite fraction after regeneration process, temperature of preheating: a) $20^{\circ} \mathrm{C}$, b) $100^{\circ} \mathrm{C}$, c) $200^{\circ} \mathrm{C}$, d) $300^{\circ} \mathrm{C}$

a)

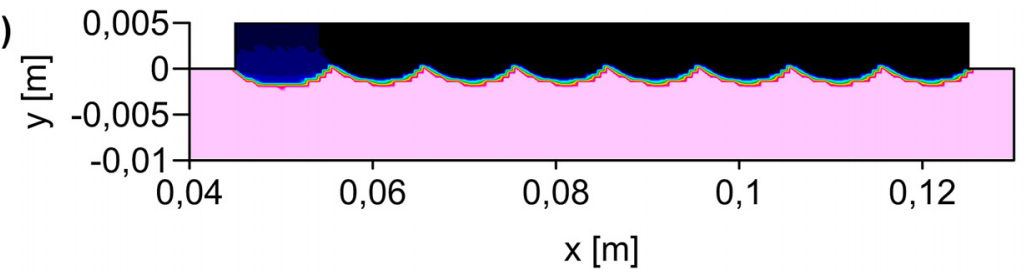

b)

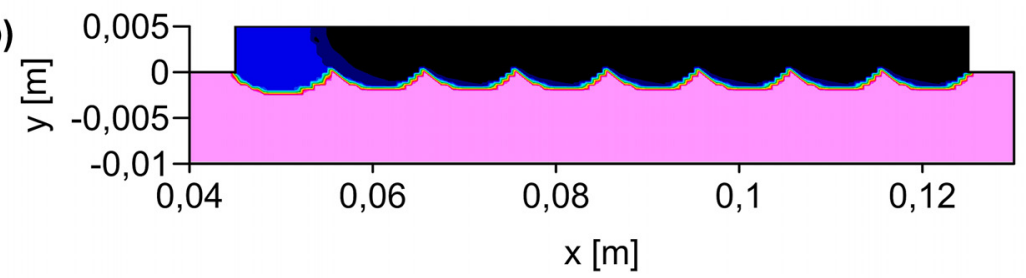

c)

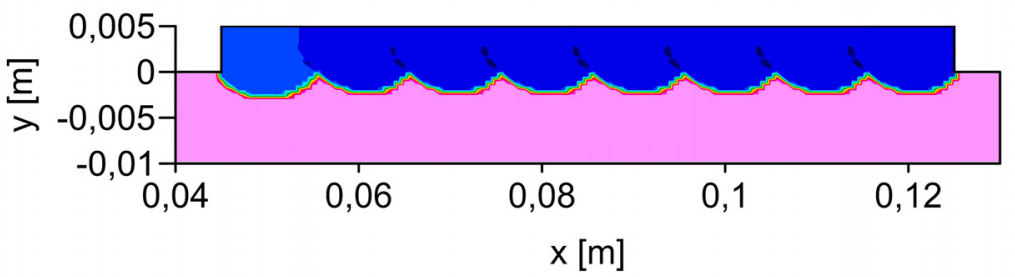

d)

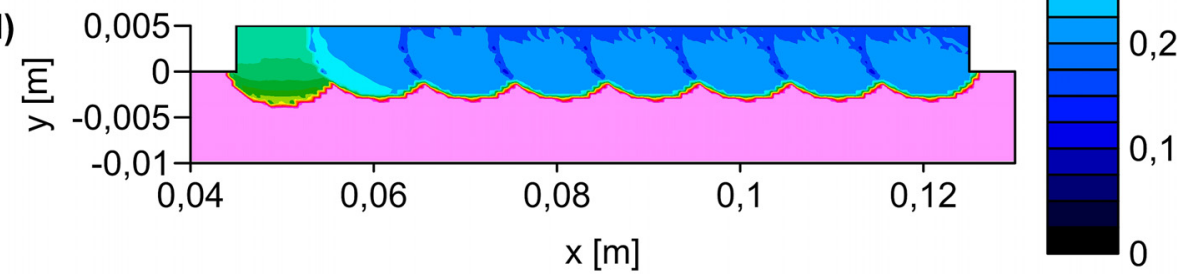

Fig. 4. Pearlite fraction after regeneration process, temperature of preheating: a) $20^{\circ} \mathrm{C}$, b) $100^{\circ} \mathrm{C}$, c) $\left.200^{\circ} \mathrm{C}, \mathrm{d}\right) 300^{\circ} \mathrm{C}$ 


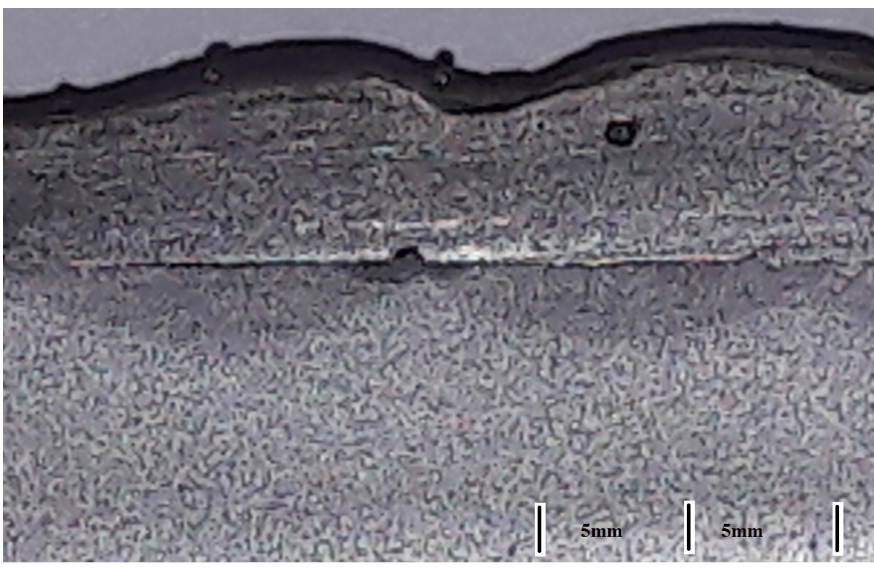

Fig. 5. Depth of penetration zone after the welding process of the construction steel

causes deepening of the fusion zone. The paper did not analyze the parameters of the process due to the depth of penetration.

The composition of hardening phases - bainite and martensite (Figs. 6,7) indicates the rightness of using preheating at least at the level of $200^{\circ} \mathrm{C}$. This provides a lower level of effective stress (Fig. 9), which has strong impact on the appearance of cracks. The areas with a higher value of plastic strains (Fig. 11) correctly show the place where the cracks can occur. The level of plastic strains is strongly disturbed by the adopted recrystallization condition. It was assumed in the model that the plastic strains are reset if the average temperature of the finite element is above 0.7 of the solidus temperature.

The distribution of plastic strains (Fig. 11) also indicates the large role of interpass tempering. A lower value of the yield point for the tempered martensite (set as the bainite) (Figs. 8, 10) is the reason for the lack of cracks between the padding weld. The cracks in the unfavorable distribution of structural and thermal strains may occur in the cross-section of the padding weld.

\section{Conclusion}

The presented numerical model makes it possible obtain the information about the state stress and the distribution of the phase in elements made of medium carbon steel regenerated by the base material. The fraction of martensite (close to 100\%) (Fig. 7a) for the temperature of an element that equals $T_{0}=20^{\circ} \mathrm{C}$ causes a significant concentration of stresses reaching over $700 \mathrm{MPa}$ (Fig. 9a). The low share of bainite (Fig. 6a), at the level of a few percent, can cause the initialization of cracks inside the martensite structure. The forming structure in this temperature may be specified as brittle, less impact resistant and susceptible to high and low tempering. On the other hand, obtained results can be used for the material preheating above $200^{\circ} \mathrm{C}$ giving the structure of bainite (more than $80 \%$ bainite) (Fig. 6d) with a small amount of martensite and tempering martensite (20\%) (Fig. 7d). The level of

a)

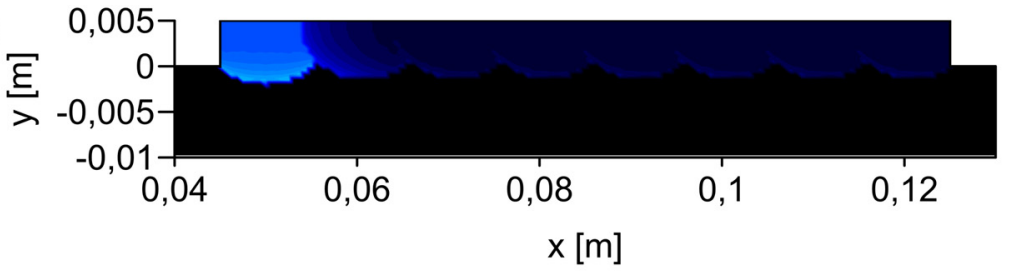

b)

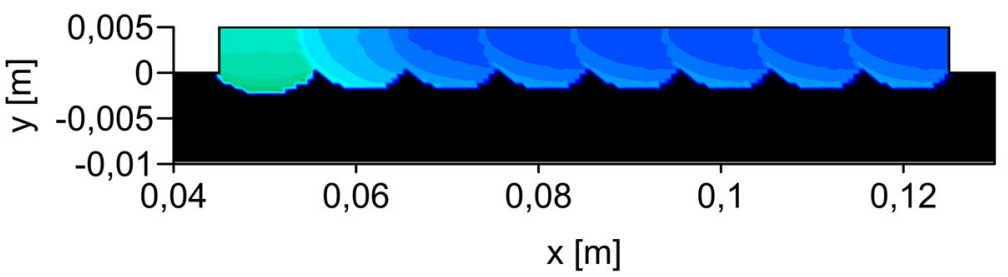

c)

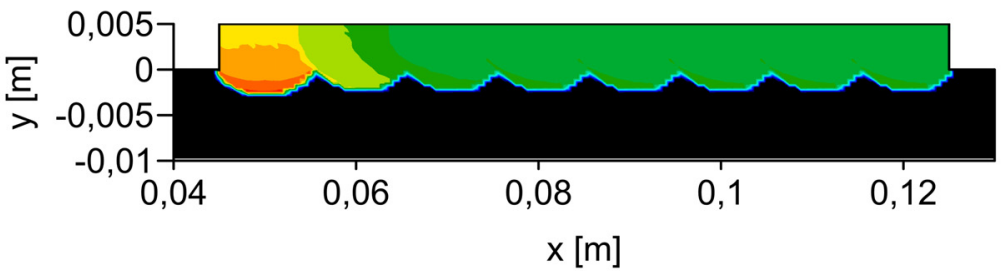

d)
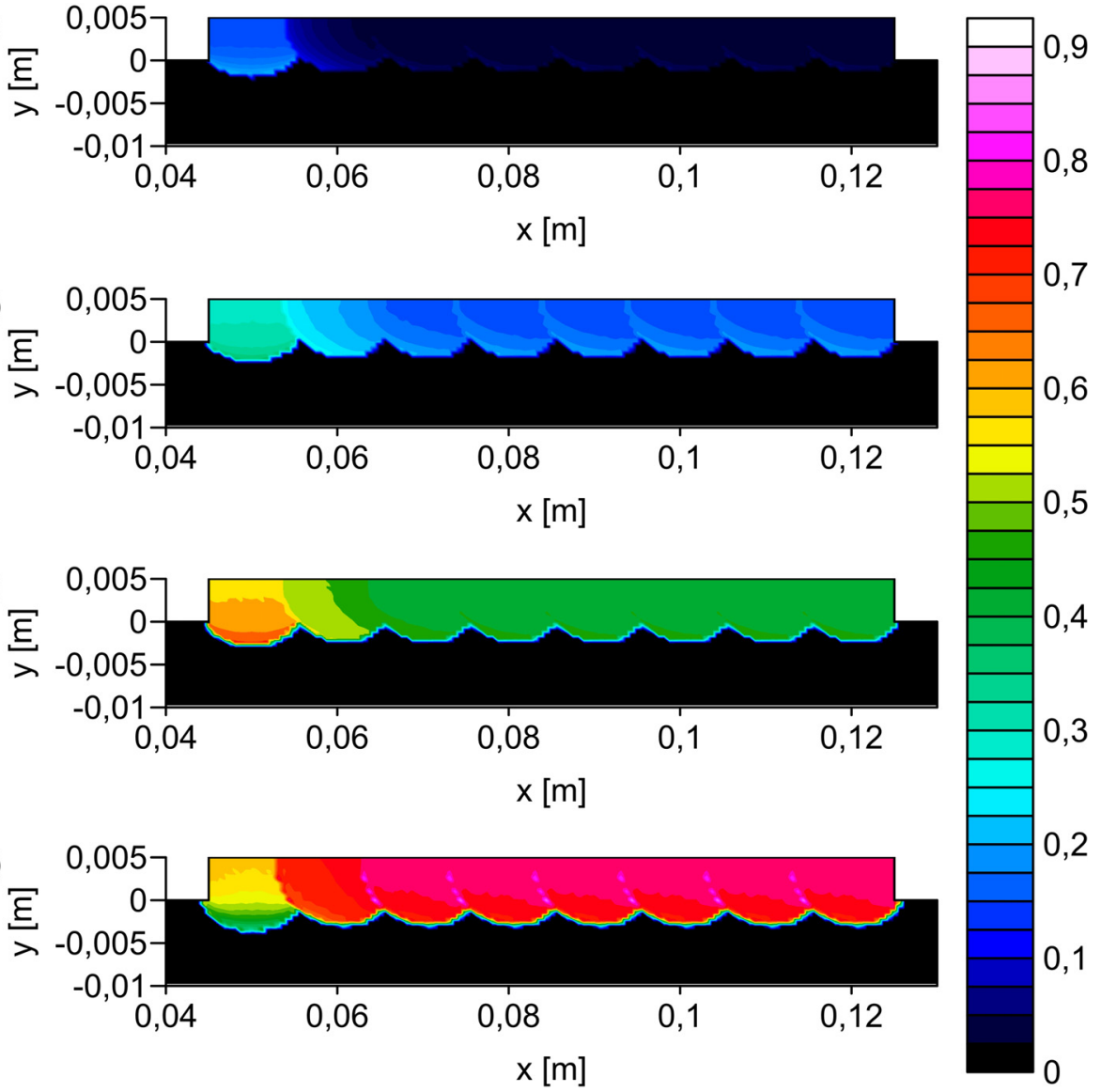

Fig. 6. Bainite fraction after regeneration process, temperature of preheating: a) $20^{\circ} \mathrm{C}$, b) $100^{\circ} \mathrm{C}$, c) $200^{\circ} \mathrm{C}$, d) $300^{\circ} \mathrm{C}$ 
a)

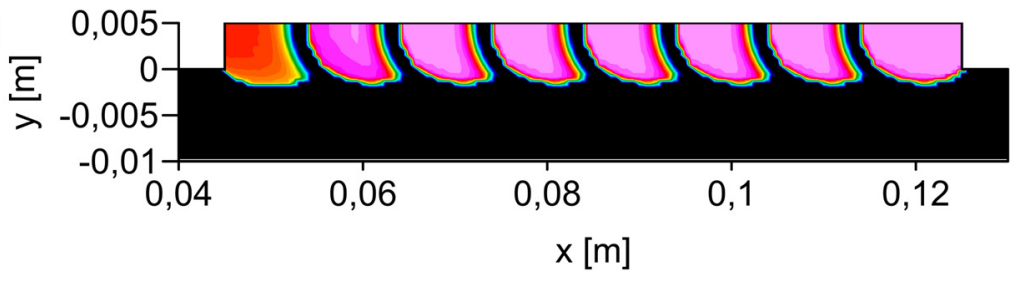

b)

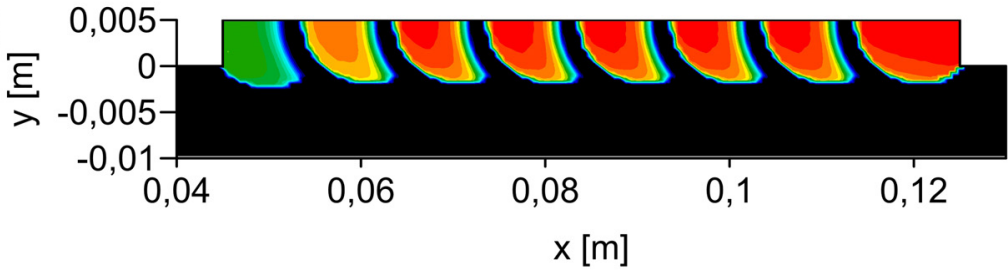

c)

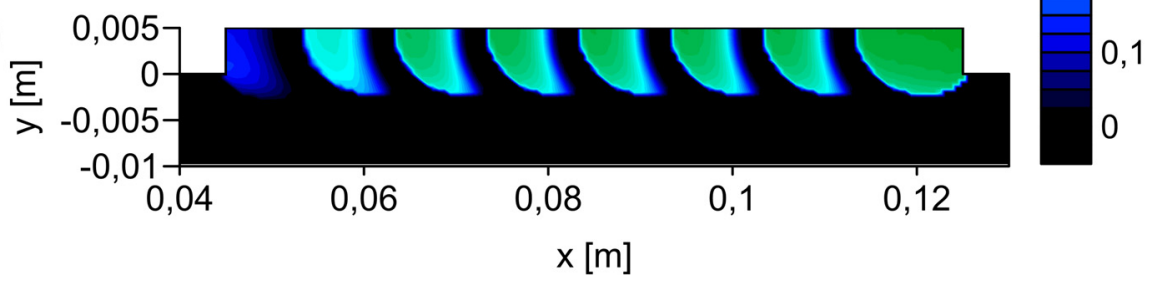

Fig. 7. Martensite fraction after regeneration process, temperature of preheating: a) $20^{\circ} \mathrm{C}$, b) $100^{\circ} \mathrm{C}$, c) $200^{\circ} \mathrm{C}$

a)

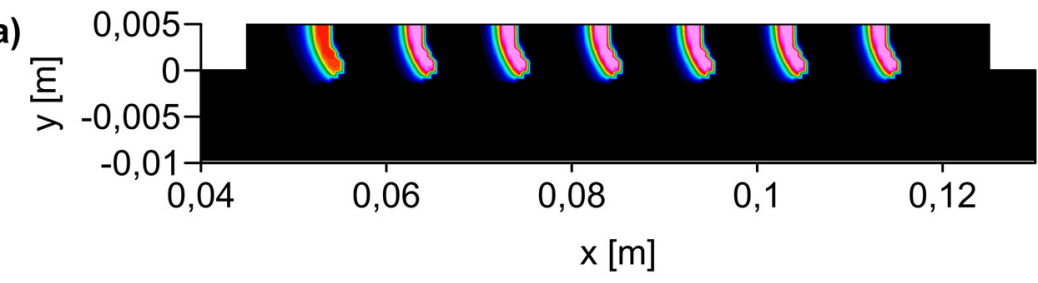

b)

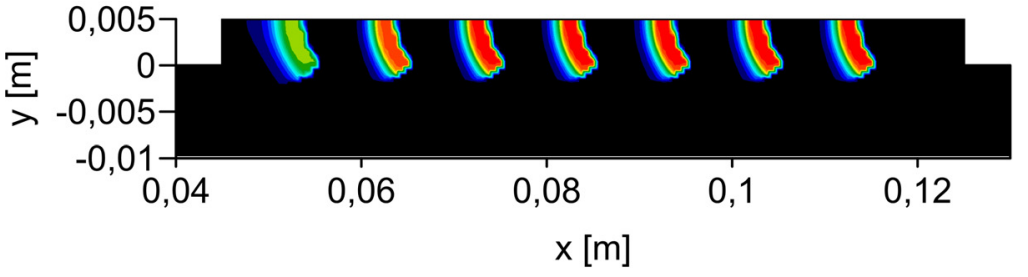

c)

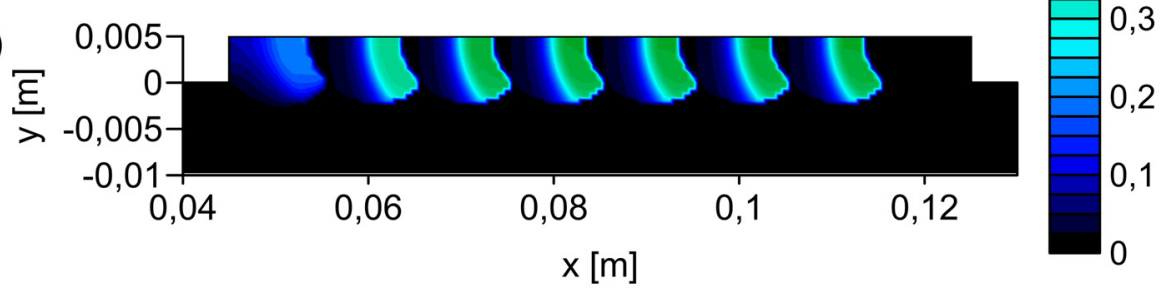

Fig. 8. Tempered martensite fraction after regeneration process, temperature of preheating: a) $20^{\circ} \mathrm{C}$, b) $100^{\circ} \mathrm{C}$, c) $200^{\circ} \mathrm{C}$

residual stress (for an elemental ready preheated to the temperature of $200^{\circ} \mathrm{C}$ ) does not achieve $500 \mathrm{MPa}$ (Fig. 9c). Taking into account the further treatment of the welded element and the value of yield point (Fig. 10), the initial temperature of the element should be above $200^{\circ} \mathrm{C}$. The level of plastic strain (Fig. 11), particularly in the interpass areas, is several times higher when the element has a temperature of $20^{\circ} \mathrm{C}$ than when the temperature is above $200^{\circ} \mathrm{C}$.

The analysis of results gives the possibility to select an appropriate preheating temperature for economic as well as technological reasons. The tested material is difficult to regen- erate. The presented analysis allows one to evaluate if defects after regeneration may occur. The described mathematical model can be used in the selection of the parameters of process such as: the preheating temperature, geometry of the padding weld and the choice of the cooling medium. All of the presented results have been obtained from the original application based on the finite element method. This application allows one to perform the simulation of regeneration of elements made of C45 steel in order to evaluate the possibility to crack and also the dimensional changes of the regenerated parts. 
a)

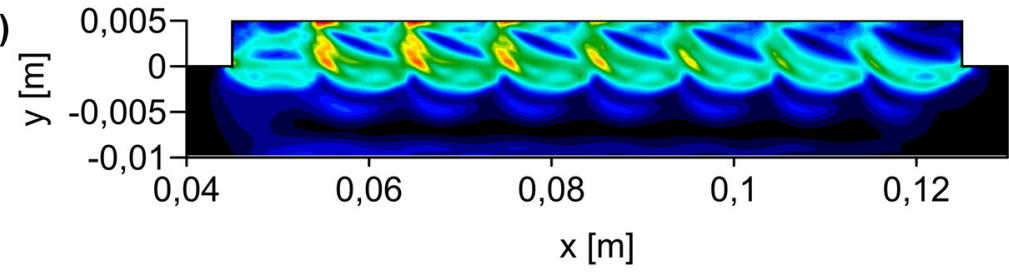

b)

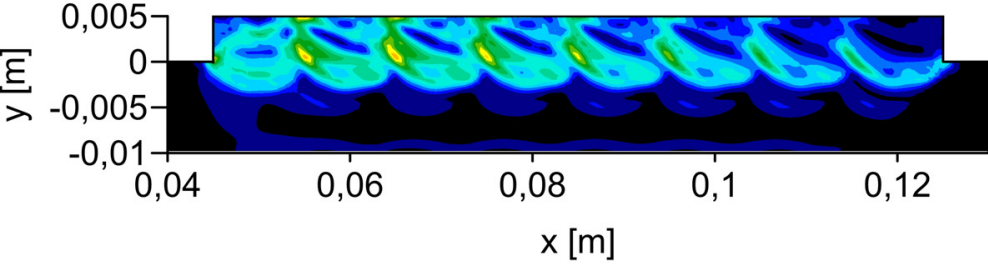

c)

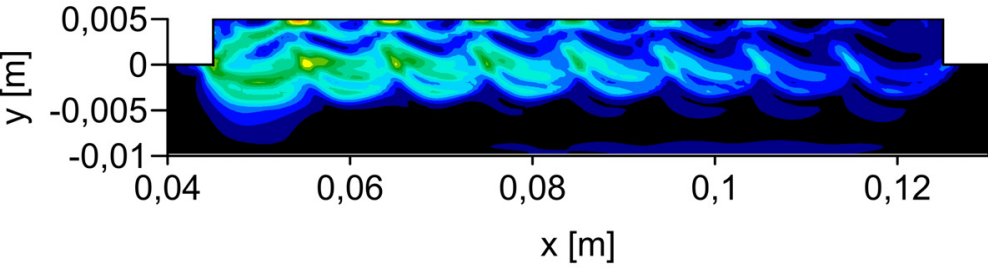

d)

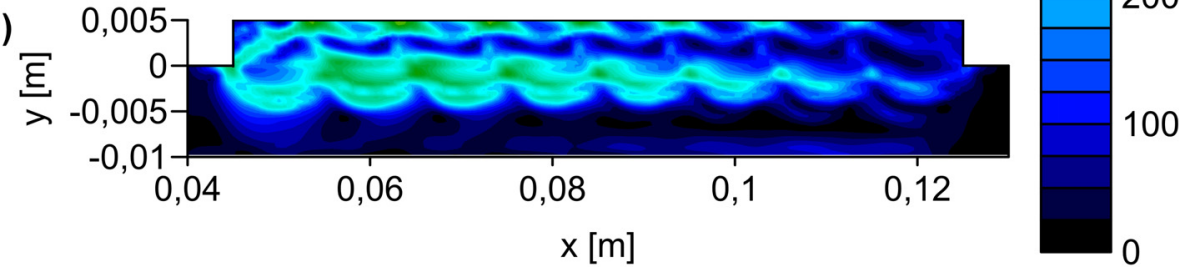

Fig. 9. Effective stresses [MPa] after regeneration process, temperature of preheating: a) $20^{\circ} \mathrm{C}$, b) $100^{\circ} \mathrm{C}$, c) $200^{\circ} \mathrm{C}$, d) $300^{\circ} \mathrm{C}$

a)

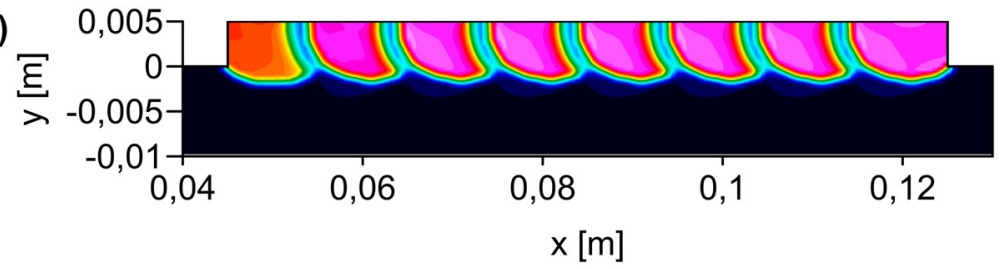

b)

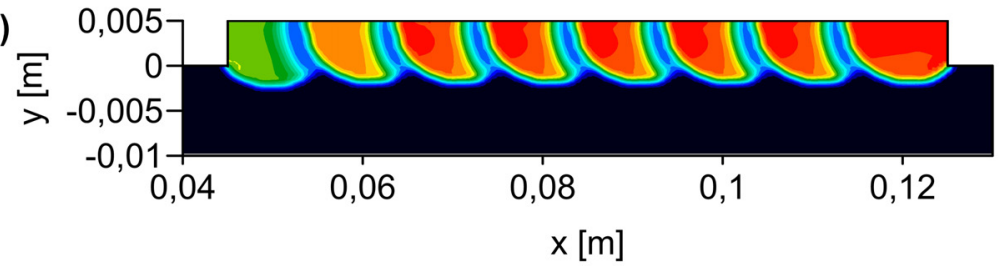

c)

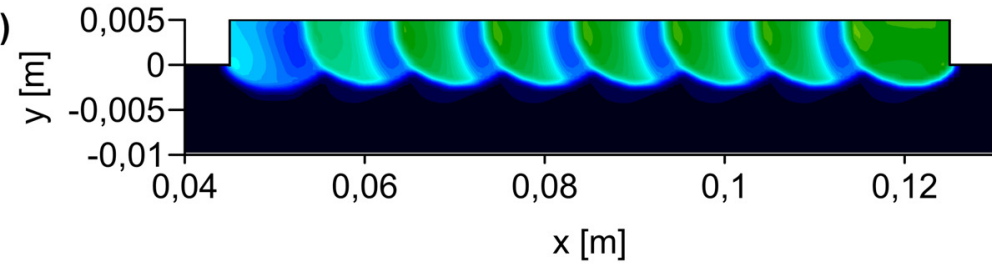

d)

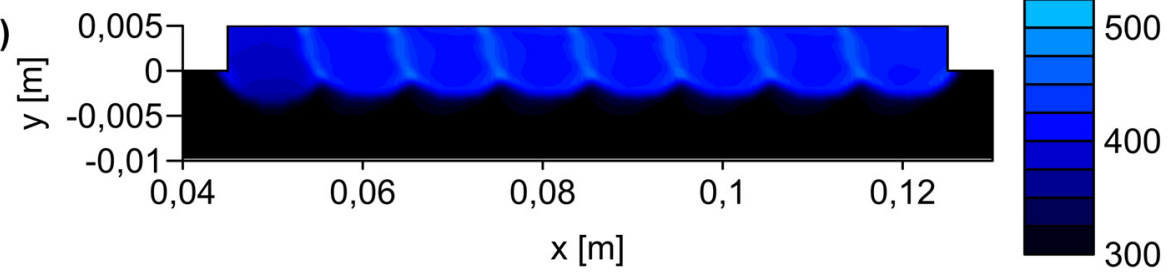

Fig. 10. Yield point $[\mathrm{MPa}]$ after regeneration process, temperature of preheating: a) $20^{\circ} \mathrm{C}$, b) $100^{\circ} \mathrm{C}$, c) $200^{\circ} \mathrm{C}$, d) $300^{\circ} \mathrm{C}$ 
a)

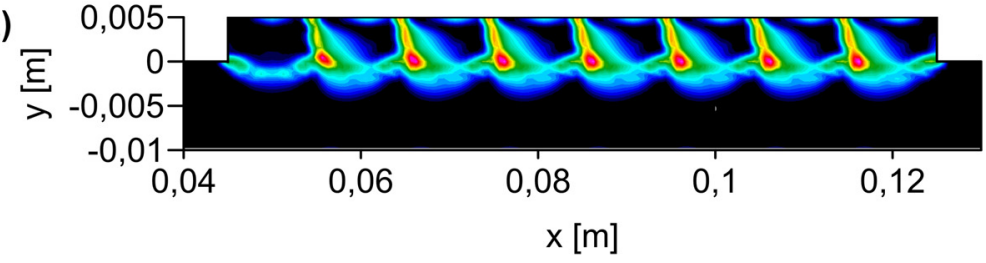

b)

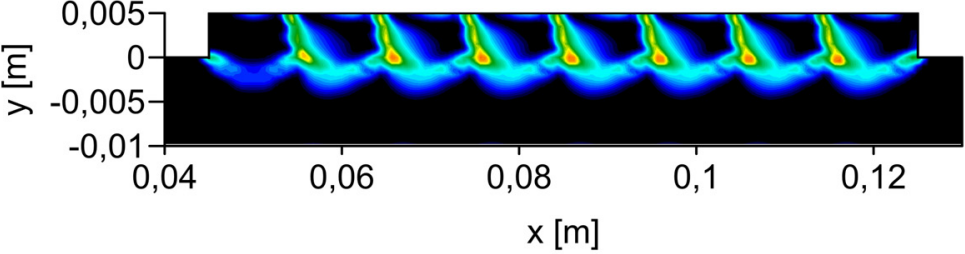

c)

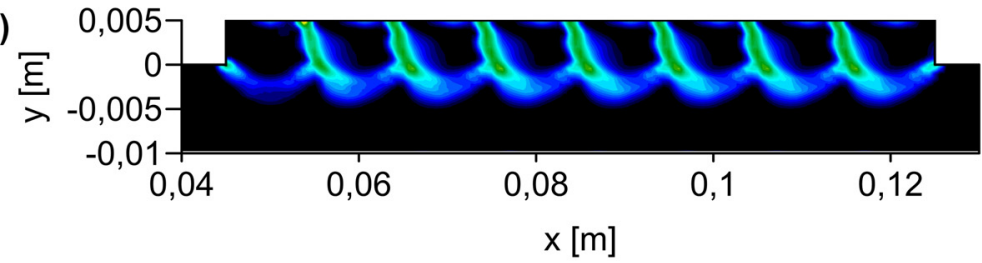

d)

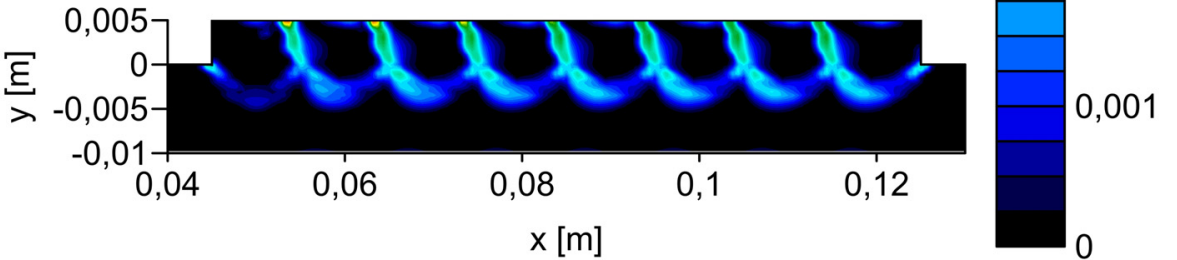

Fig. 11. Effective plastic strain after regeneration process, temperature of preheating: a) $20^{\circ} \mathrm{C}$, b) $100^{\circ} \mathrm{C}$, c) $200^{\circ} \mathrm{C}$, d) $300^{\circ} \mathrm{C}$

\section{REFERENCES}

[1] M. Avrami, J.Chem. Phys. 7, 1103-1112 (1939).

[2] R. Bęczkowski, Metalurgija 56 (1-2), 59-62 (2017).

[3] R. Bęczkowski, M. Gucwa, Weld.Technol. Rev. 87 (9), 43-46(2015).

[4] R. Bęczkowski, M. Gucwa, J. Wróbel, A. Kulawik, American Institute of Physics 1738, Melville 2016.

[5] R. Bęczkowski, M. Gucwa, Arch. Foundry Engineer. 16 (4), 23-28 (2016).

[6] A. Bokota, A. Kulawik, Arch. Metall. Mater. 52(2), 337-346(2007).

[7] A. Bokota, Modelling of solidification and cooling of two-component metal alloys. Fields of temperature, concentrations and stresses, Monograph nr 79, 2001 Wydawnictwo Politechniki Czestochowskiej,Czestochowa.

[8] J. Brózda, Stale konstrukcyjne i ich spawalność, 2009 Instytut Spawalnictwa, Gliwice.

[9] M. Coret, A. Combescure, Int. J. Mech. Sci. 44, 1947-1963 (2002).

[10] T. Chmielewski, D. Golański, G. Gontarz, Weld. Technol. Rev. 83(12), 59-64 (2011).

[11] F.D. Fischer, G. Reinsner, E. Werner, K. Tanaka, G. Cailletaud, T. Antretter, Int. J. Plasticity 16, 723-748 (2000).

[12] ISO 5817:2014 Welding - fusion-welded joints in steel, nickel, titanium and their alloys (beam welding excluded) - quality levels for imperfections.

[13] ISO 15614-7:2009 Specification and qualification of welding procedures for metallic materials - Welding procedure test - Part 7: Overlay welding.
[14] D.P. Koistinen, R.E. Marburger, Acta Metall. 7, 59-60 (1959).

[15] M. Kleiber, Finite element method in nonlinear continuum mechanics, 1985, PWN, Warszawa-Poznań

[16] V.D. Kuzniecow, P.W. Popowicz, Weld. Technol. Rev. 83 (10), 4-7 (2011).

[17] C. Li, Y. Wang, H. Zhan, T. Han, B. Han, W. Zhao, Mater. Design 31, 3366-3373 (2010)

[18] P.F. Mendez, N. Barnes, K. Bell, S.D. Borle, S.S. Gajapathi, S.D. Guest, H. Izadi, A.K. Gol, G. Wood, J. Manuf. Process. 16, 4-25 (2014).

[19] J. Orlich, A. Rose, P. Wiest, Atlas zur Wärmebehandlung von Stähle, III Zeit Temperatur Austenitisierung Schaubilder, 1973 Verlag Stahleisen MBH, Düsseldorf.

[20] M. Różański, W. Gawrysiuk, Weld. Technol. Rev. 79 (9), 7-12 (2007).

[21] J. Szajnar, A. Walasek, C. Baron, Arch. Metall. Mater. 58 (3), 931-936 (2013), DOI: 10.2478/amm-2013-0104.

[22] L. Taleb, N. Cavallo, F. Waeckel, Int. J. Plasticity 17, 1-20 (2001).

[23] J. Winczek, Procedia Eng. 136, 108-113 (2016).

[24] J. Winczek, E. Gawrońska, Metalurgija 55 (2), 225-228 (2016).

[25] J. Winczek, A. Kulawik, Metalurgija 51 (1), 9-12 (2012).

[26] F. Wever, A. Rose, Atlas zur Wärmebehandlung von Stähle, I Zeit Temperatur Umwandlungs Schaubilder, 1961Verlag Stahl Eisen $\mathrm{MBH}$, Düsseldorf.

[27] O.C. Zienkiewicz, R.L. Taylor, The finite element method, 2000 Oxword: Butterworth-Heinemann

[28] J. Zimmerman, D. Golański, T. Chmielewski, W. Włosiński, Weld. Technol. Rev. 85 (1), 12-16 (2013). 